\title{
Genotype by environment interaction using AMMI model and estimation of additive and epistasis gene effects for 1000-kernel weight in spring barley (Hordeum vulgare L.)
}

\author{
Jan Bocianowski ${ }^{1}$ (D) Tomasz Warzecha $^{2} \cdot$ Kamila Nowosad $^{3} \cdot$ Roman Bathelt $^{2}$
}

Received: 19 October 2018 / Revised: 20 February 2019 / Accepted: 5 March 2019 /Published online: 15 March 2019

(C) The Author(s) 2019

\begin{abstract}
The objective of this study was to assess genotype by environment interaction for 1000-kernel weight in spring barley lines grown in South Poland by the additive main effects and multiplicative interaction model. The study comprised of 32 spring barley (Hordeum vulgare L.) genotypes (two parental genotypes — breeding line 1 N86 and doubled haploid (DH) line RK63/1, and 30 $\mathrm{DH}$ lines derived from $\mathrm{F}_{1}$ hybrids), evaluated at six locations in a randomized complete block design, with three replicates. 1000kernel weight ranged from $24.35 \mathrm{~g}$ (for R63N/42 in 2011) to $61.46 \mathrm{~g}$ (for R63N/18 in 2008), with an average of $44.80 \mathrm{~g}$. AMMI analyses revealed significant genotype and environmental effects as well as GE interaction with respect to 1000-kernel weight. In the analysis of variance, $16.86 \%$ of the total 1000 -kernel weight variation was explained by environment, $32.18 \%$ by differences between genotypes, and $24.50 \%$ by GE interaction. The lines R63N/61, R63N/22, and R63N/1 are recommended for further inclusion in the breeding program because their stability and the highest averages of 1000-kernel weight. The total additive effect of all genes controlling the trait and the total epistasis effect of 1000-kernel weight were estimated. Additive gene action effects based on DH lines were always larger that this parameter estimated on the basis of parental lines. Estimates of additive gene action effects based on the all DH lines were significantly larger than zero in each year of study. Epistasis effects based on all DH lines were statistically significant in 2011 and 2013.
\end{abstract}

Keywords Hordeum vulgare L. · 1000-kernel weight · AMMI · Stability · Genetic parameters · Doubled haploid lines

\section{Introduction}

Environmental conditions might possess various influence on genotype; therefore, certain genotype responses could differ depending on various environment-forming genotype-byenvironment (GE) interaction. The phenotypic presentation

Communicated by: Barbara Naganowska

Jan Bocianowski

jan.bocianowski@up.poznan.pl

1 Department of Mathematical and Statistical Methods, Poznań University of Life Sciences, Wojska Polskiego 28, 60-637 Poznań, Poland

2 Department of Plant Breeding and Seed Science, University of Agriculture in Krakow, Łobzowska 24, 31-140 Kraków, Poland

3 Department of Genetics, Plant Breeding and Seed Production, Wrocław University of Environmental and Life Sciences, Grunwaldzki 24A, 53-363 Wrocław, Poland of different genotypes could be constant in various environments, whereas some others expose significant variation over diverse environments. The difference between the phenotypic, experiential assessment and the value predictable from the theoretical model of observations that takes into account the general mean as well as genotypic and environmental main effects can be defined statistically as GE interaction. Numerous phenotypic characteristics determined in multienvironment studies, for example yield and its items, expose variation in presentation in different environmental settings; consequently, cultivars may be classified as unstable. The various performance of cultivars might be cleared up with environmental main effect utilization, while the mean values of studied characteristics of all genotypes considerably differ amid environments, and partly can be created by GE interactions, while the differences among genotypes are unequable throughout environments. Breeder and farmers desire constant cultivars or cultivars only slightly modified by environment. Genotype stability or instability might be estimated with a series of trial application. Numerous authors have proposed 
statistical methods for estimating the manner of genotype reaction to diverse environmental condition (Neyman 1932; Yates and Cochran 1938; Mather and Jones 1958; Finlay and Wilkinson 1963; Eberhart and Russell 1966; Wricke and Weber 1986). The reaction of certain genotypes in diverse environments could be determined in series of trials with application of methods generated by Kaczmarek (1986) and Caliński et al. (1987). Based on above methods, GE effect connected with every genotype (computed by the assessment of the adequate $F$-statistic) is the assessment of stability, and the regression of the GE interaction effects on the tentative means originated from various environments (assessed by the value of the adequate $F$-statistic) is the estimation of adaptability. The calculation of stability articulated in GE interaction with the $F$ statistic value application can be traced back to the methods initially developed by Caliński (1960) and in parallel by Wricke (1962), whereas the $F$-statistic for the regression, measured as the determination of adaptability, is connected to the idea of Finlay and Wilkinson (1963) and Eberhart and Russell (1966). Barley (Hordeum vulgare L.) after rice, wheat and maize are fourth cereal crops in the world (https://www. statista.com/statistics/263977/world-grain-production-by-type/ accessed 21.06.2018). Even if it is acknowledged to be acclimated to a wide type of environmental surroundings (e.g. , MacGregor and Bhatty (1993)) numerous research have showed a significant impact of environmental conditions and GE interaction on phenotypic presentation of agronomically essential features (Eagles et al. 1995; Kaczmarek et al. 1999; Chełkowski et al. 2000; Warzecha et al. 2011). Barley yield and its structure, as well as other traits connected with barley kernel utilization as food and feed, might be affected by environmental conditions divided into abiotic factors (temperature, precipitation, water contamination, air pollution, etc.) and biotic factors (fungal, viral bacterial pathogen infection, pest damage). For instance, harmful diseases caused by the Fusarium species in barley worldwide like Fusarium seedling blight (FSB) and Fusarium head blight (FHB) (Warzecha et al. 2011; Marin et al. 2013; Nielsen et al. 2014). Grain yield and its quality reduction are caused by the disease as a result of contamination with mycotoxins, which are responsible for mycotoxicoses in humans and domestic animals (Buerstmayr et al. 2009; Marin et al. 2013). The malting and brewing industries also suffer because of contaminated grains (Desjardins 2006; Ma et al. 2009). Response of genotypes on unstable abiotic factors can be assessed by performing research within a number of years and/or in diverse localization, while the result of biotic stresses (e.g., viral, bacterial, or fungal pathogens) could be studied predominantly with artificial infection application.

One of the major aims in spring barley breeding has constantly been rising 1000-kernel weight as a way of increasing yield. An enhanced awareness of genetic determination of 1000-kernel weight can help the breeders to manage the genetic improvement for the crop. 1000-kernel weight is a very complex quantitative feature, and its expression is controlled also in complex way as the result of genotype, environmental factors, and the GE interaction. Complexity of 1000-kernel weight is a consequences of diverse response of genotypes on unstable environmental conditions during plant growth. The GE interaction is frequently analyzed by the additive main effects and multiplicative interaction (AMMI) model (Zobel et al. 1988). The AMMI model combines the analysis of variance for the genotype and environmental main effects and the principal component analysis (PCA) with multiplicative indices in a particular single analysis.

The objectives of this study were (1) to assess genotype by environment interaction for 1000-kernel weight in spring barley (Hordeum vulgare L.) grown in South Poland by the AMMI model and (2) to estimate the parameters connected with the additive and additive-by-additive interaction (epistasis) gene action.

\section{Materials and methods}

The material for the studies covered 32 spring barley (Hordeum vulgare L.) genotypes: two parental genotypes (breeding line 1N86 and DH line RK63/1 derived from barley cultivars Roland and Kristal), and $30 \mathrm{DH}$ lines derived from $\mathrm{F}_{1}$ hybrids. DH lines were developed by Hordeum bulbosum technique. Standard procedures were applied for crossing $H$. vulgare with $H$. bulbosum and in vitro culture of immature embryos (Kasha and Kao 1970; Devaux 1986).

Field experiments were carried out over 6 years: 2008 2013 at Prusy, South Poland (near Kraków, 50 06' 52" N, $20^{\circ} 04^{\prime} 23^{\prime \prime}$ E). During each year, the experiment with $g=32$ genotypes was carried out in a randomized block design, with three replications. In each plot, seeds were sown in six rows $2 \mathrm{~m}$ long, $20 \mathrm{~cm}$ apart, with each row containing 200 seeds. At full maturity, spikes were harvested manually and 1000-kernel weight was examined. Mean values of temperature and precipitation for seasons of experiment in Prusy near Kraków are presented in Table 1. A two-way fixed effect model was fitted to determine the magnitude of the main effects of variation and their interaction on 1000-kernel weight. Least squares means were simultaneously produced for the AMMI model. The model first fits additive effects for the main effects of genotypes $(\mathrm{G})$ and environments (E) followed by multiplicative effects for GE interaction by principal component analysis. The traditional AMMI model for fixed effects (Gauch and Zobel 1990; Nowosad et al. 2016) is given by:

$y_{g e}=\mu+\alpha_{g}+\beta_{e}+\sum_{n=1}^{N} \lambda_{n} \gamma_{g n} \delta_{e n}+Q_{g e}$,

where $y_{g e}$ is the 1000-kernel weight mean of genotype $g$ in environment $e, \mu$ is the grand mean, $\alpha_{g}$ is the genotypic mean 
Table 1 Meteorological data for seasons of experiments (mean value)

\begin{tabular}{cccccc}
\hline & \multicolumn{2}{l}{ Temperature $\left({ }^{\circ} \mathrm{C}\right)$} & & \multicolumn{2}{l}{ Precipitation $(\mathrm{mm})$} \\
\cline { 2 - 3 } \cline { 5 - 6 } Year & June & July & & June & July \\
\hline 2008 & 18.5 & 19.1 & & 25.9 & 142.1 \\
2009 & 16.1 & 20.1 & & 163.3 & 71.67 \\
2010 & 17.6 & 20.8 & & 135.1 & 105.2 \\
2011 & 18.1 & 17.7 & & 44.4 & 194.4 \\
2012 & 17.7 & 20.5 & & 143.1 & 68.7 \\
2013 & 17.6 & 19.2 & & 213.1 & 27.2 \\
Mean & 17.6 & 19.6 & & 120.8 & 101.5 \\
\hline
\end{tabular}

Source: Date of the Department of Crop Production, Agricultural University in Kraków, Substation Prusy $50.13333^{\circ} \mathrm{N}, 20.0833^{\circ} \mathrm{E}$

deviations, $\beta_{e}$ is the environmental mean deviations, $N$ is the number of PCA axis retained in the adjusted model, $\lambda_{n}$ is the eigenvalue of the PCA axis $n, \gamma_{g n}$ is the genotype score for PCA axis $n, \delta_{e n}$ is the score eigenvector for PCA axis $n$, and $Q_{g e}$ is the residual, including AMMI noise and pooled experimental error. Expected distribution of $Q_{g e}$ is normal.

The AMMI stability value (ASV) was used to compare the stability of genotypes as described by Purchase et al. (2000):

$A S V=\sqrt{\left[\frac{S S_{I P C A 1}}{S S_{I P C A 2}}\left(I P C A_{1}\right)\right]^{2}+\left(I P C A_{2}\right)^{2}}$,

where $S S$ is the sum of squares, IPCA1 and IPCA2 are the first and the second interaction principal component axes, respectively; and the $I P C A_{1}$ and $I P C A_{2}$ scores were the genotypic scores in the AMMI model. ASV is the distance from zero in a two-dimensional scatterplot of $I P C A_{1}$ scores against $I P C A_{2}$ scores. Since the $I P C A_{1}$ score contributes more to GE sum of square, it has to be weighted by the proportional difference between $I P C A_{1}$ and $I P C A_{2}$ scores to compensate for the relative contribution of $I P C A_{1}$ and $I P C A_{2}$ total GE sum of squares. The higher the IPCA score, either negative or positive, the more specifically adapted a genotype is to certain environments. Lower ASV score indicates a more stable genotype across environments.

Genotype selection index (GSI) was calculated for each genotype which incorporates both mean 1000-kernel weight and ASV index in single criteria $\left(\mathrm{GSI}_{i}\right)$ as (Farshadfar and Sutka 2003):

$\mathrm{GSI}_{\mathrm{i}}=\mathrm{RY}_{\mathrm{i}}+\mathrm{RASV}_{i}$,

where $\mathrm{GSI}_{\mathrm{i}}$ is genotype selection index for $i$ th genotype, $\mathrm{RY}_{\mathrm{i}}$ is rank of mean 1000-kernel weight for $i$ th genotype, $\mathrm{RASV}_{\mathrm{i}}$ is rank for the AMMI stability value for the $i$ th genotype.

Estimation of the additive gene effect and additive-byadditive interaction of homozygous loci (epistasis) effect on the basis of phenotypic observations requires identification of groups of extreme DH lines, i.e., lines with the minimal and maximal expression of the observed trait (Choo and Reinbergs 1982). The group of minimal lines consists of the lines which contain, theoretically, only alleles reducing the value of the trait. Analogously, the group of maximal lines contains the lines which have only alleles increasing the trait value. In this paper, we identify the groups of extreme lines using the quantile method (Bocianowski et al. 1999), in which lines with the mean values smaller (bigger) than $0.03(0.97)$ quantile of the empirical distribution of means are assumed as minimal (maximal) lines. The chosen quantiles 0.03 and 0.97 are the results of previously study (Bocianowski et al. 1999). The total additive effect $a_{D H}$ of all genes controlling the trait and the total additive-by-additive interaction effect $a a_{D H}$ may be estimated by the formulas (Bocianowski and Krajewski 2009; Bocianowski 2012b):

$\hat{a}_{D H}=\frac{1}{2}\left(\bar{L}_{\max }-\bar{L}_{\min }\right)$

and

$\hat{a a_{D H}}=\frac{1}{2}\left(\bar{L}_{\max }+\bar{L}_{\min }\right)-\bar{L}$,

where $\bar{L}_{\min }$ and $\bar{L}_{\text {max }}$ denote the means for the groups of minimal and maximal DH lines, respectively, and $\bar{L}$ denotes the mean for all DH lines. Additionally, the additive effects were estimated on the basis of parental observations:

$\hat{a}_{\text {Parents }}=\frac{1}{2}\left(P_{1}-P_{2}\right)$,

where $P_{1}$ and $P_{2}$ are the means for better- and lower-scoring parents, respectively. The test statistics to verified hypotheses about genetic parameters different than zero are given by:

$F_{a}=\frac{M S_{a}}{M S_{e}}$ and $F_{a a}=\frac{M S_{a a}}{M S_{e}}$,

where $M S_{a}$ denotes mean square for parameter $a, M S_{a a}$ denotes mean square for epistasis $a a, M S_{e}$ denotes mean square for residual.

All the analyses were conducted using the GenStat v. 18 statistical software package.

\section{Results}

In the analysis of variance, the sum of squares for genotype main effect accounted for $32.18 \%$ of the general sum, and this part had the maximum impact on 1000-kernel weight. The differences between environmental conditions clarified $16.86 \%$ of the total 1000 -kernel weight variation, whereas the effects of GE interaction clarified $24.50 \%$ (Table 2). Values for the three major components were highly significant 
Table 2 Analysis of variance of main effects and interactions for spring barley (Hordeum vulgare L.) lines 1000-kernel weight

\begin{tabular}{lrcccl}
\hline Source of variation & d.f. & Sum of squares & Mean squares & $F$-statistic & Variability explained (\%) \\
\hline Genotypes & 31 & 13,210 & 426.1 & $16.16^{* * * *}$ & 32.18 \\
Environments & 5 & 6920 & 1384 & $15.84 * * *$ & 16.86 \\
Interactions & 155 & 10,057 & 64.9 & $2.46^{* * * *}$ & 24.50 \\
IPCA1 & 35 & 4640 & 132.6 & $5.03^{* * *}$ & 46.14 \\
IPCA2 & 33 & 2065 & 62.6 & $2.37^{* * *}$ & 20.53 \\
IPCA3 & 31 & 1866 & 60.2 & $2.28^{* * *}$ & 18.55 \\
Residuals & 56 & 1486 & 26.5 & 1.01 & \\
Error & 372 & 9810 & 26.4 & & \\
\hline
\end{tabular}

$* * * P<0.001 . I P C A$, principal component of interaction too. The three principal components of GE interaction possessed together $85.22 \%$ of the total effect it had on the variation of 1000-kernel weight. The first principal component (IPCA1) oscillated for $46.16 \%$ of the variation formed by interaction, IPCA 2 oscillated for $20.53 \%$, while IPCA3 oscillated for $18.55 \%$ (Fig. 1, Table 2).

The results of field trials demonstrated the impact of weather conditions, environment, and genotypes on the 1000-kernel weight of the spring barley genotypes. The 1000-kernel weight of the tested genotypes varied from $24.35 \mathrm{~g}$ (for $\mathrm{R} 63 \mathrm{~N} / 42$ in 2011) to $61.46 \mathrm{~g}$ (for R63N/18 in 2008), throughout the six seasons, with an average of $44.80 \mathrm{~g}$ (Table 3 ). The hulled line R63N/61 had the highest average 1000-kernel weight $(54.59 \mathrm{~g})$, and the hull-less line R63N/24 had the lowest $(34.80 \mathrm{~g})$. The average 1000-kernel weight per location also varied from $38.47 \mathrm{~g}$ in 2011, to $49.43 \mathrm{~g}$ in 2008 .

The AMMI1 biplot (Fig. 1) shows the stability of genotypes and environments, as well as specific GE interactions.
Among the tested genotypes, the hull-less line R63N/47 had the highest IPCA1 value of 2.684 , while the smallest value of IPCA1 was -2.534 for the hulled line R63N/74 (Fig. 1). Among the tested environments, the smallest IPCA1 value was observed in $2009(-2.783)$, while the highest value of IPCA1 was 3.868 in 2012 (Fig. 1). Genotype stability is considered as consistent reaction to changing environmental conditions, weather conditions, agronomic factors, and biotic and abiotic stresses. In this study, climatic conditions were the source of this variation component. The genotypes with specifically adaptation to certain environments were presented as four groups in Fig. 1. Meteorological conditions in the year 2012 and 2013 were similar according to temperature both in June and July but precipitation was much abundant in June 2013 with lower value in June 2012 (Table 1). The stability of tested genotypes can be evaluated according to biplot for 1000-kernel weight (Fig. 2). The lines R63N/14 and R63N/47 interacted positively with the years 2012 and 2013,
Fig. 1 Biplot for genotype by environment interaction of spring barley (Hordeum vulgare L.) lines in six environments, showing the effects of primary and secondary components (IPCA1 and IPCA2, respectively)

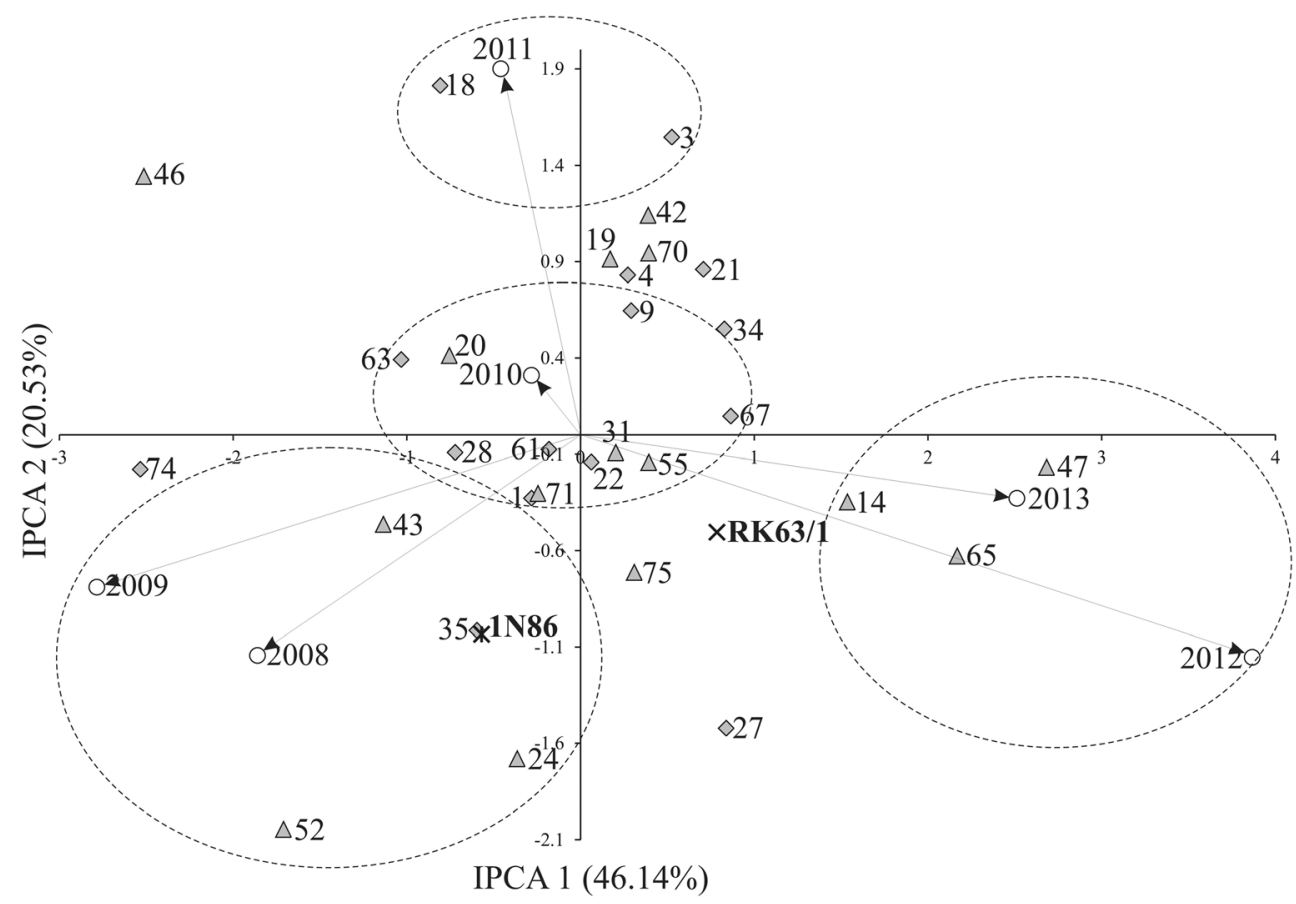




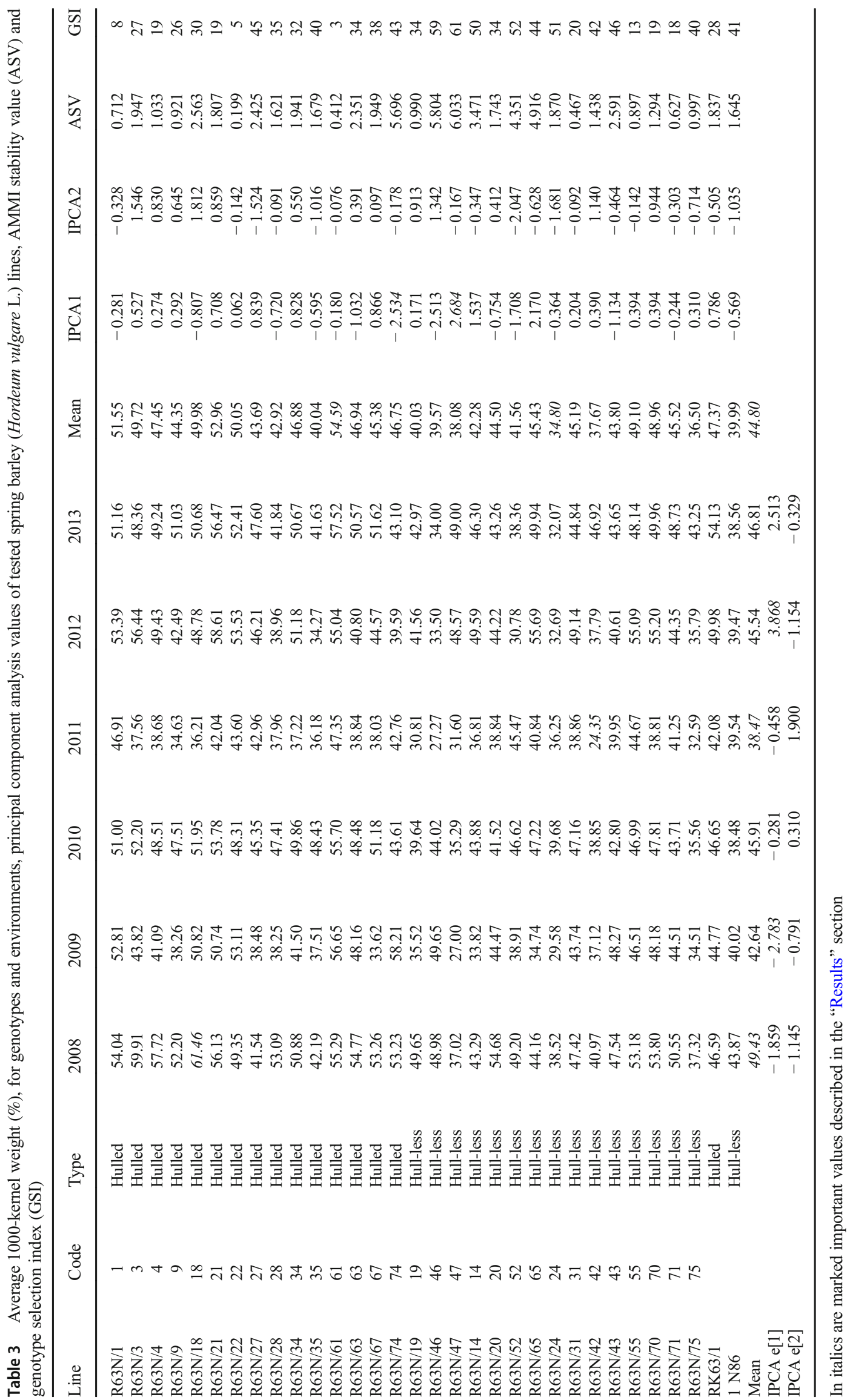


Fig. 2 Biplot for the primary component of interaction (IPCA1) and average spring barley (Hordeum vulgare L.) 1000kernel weight $(\mathrm{g})$. Vertical line at the center of biplot is the general grand mean

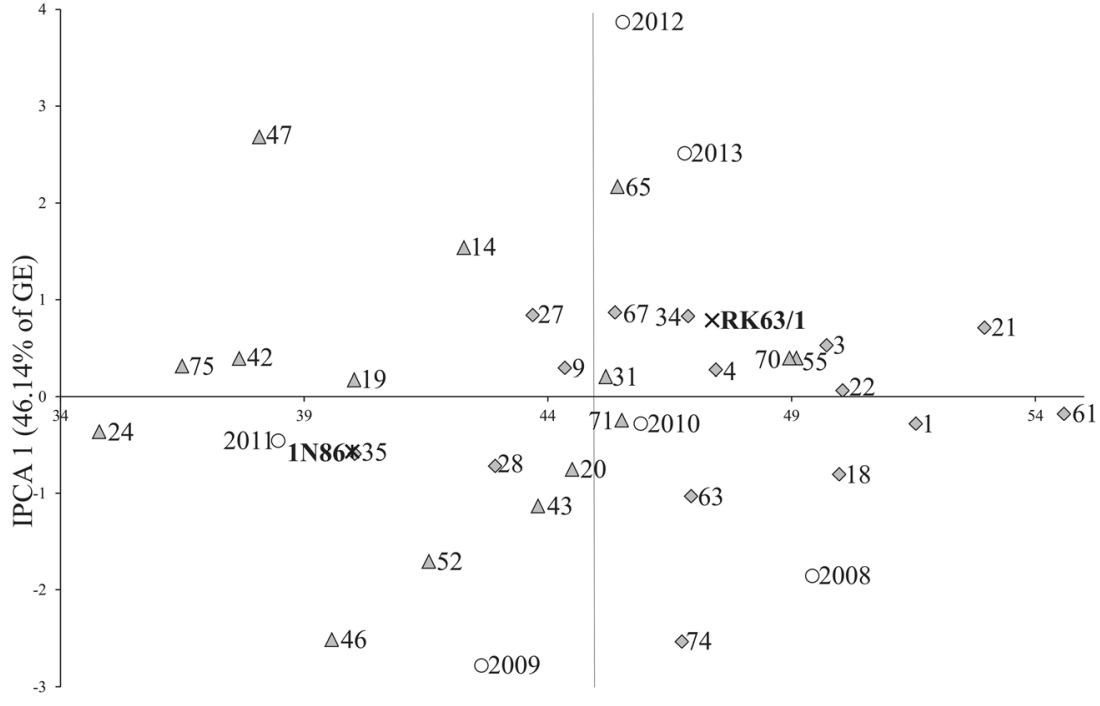

1000-kernel weight but negatively with the years 2008 and 2009 (Figs. 1 and 2). Both lines positively react to high moisture and water recourses from high precipitation in June in the years 2012 and 2013 (Table 1) that is why a positive interaction with the years 2012 and 2013 was revealed. The water conditions were quite diverse in 2008 and 2009 in June (Table 1) and the negative interaction with the years 2008 and 2009 of the lines mentioned above were detected. It could be assumed that both lines react positively to high water availability in June, and high water potential impact positively 1000-kernel weight. The lines R63N/52 and R63N/74 interacted positively with the years 2008 and 2009, but negatively with the years 2012 and 2013. The lines R63N/20 and R63N/63 interacted positively with the year 2010. The lines possessed higher 1000kernel weight when July was warmer than June and the water availability was similar in June and July since precipitation for both months were high and alike. The analysis showed that some genotypes have high adaptation; however, most of them have specific adaptability. AMMI stability values (ASV) revealed variations in 1000-kernel weight stability among the 25 genotypes (Table 3). According to Purchase et al. (2000), a stable variety is defined as one with ASV value close to zero. Consequently, the hulled lines R63N/22 and R63N/61 with ASV of 0.199 and 0.412, respectively, as well as hull-less line R63N/31 with ASV of 0.467 were the most stable, while the lines such as R63N/47, R63N/46, and R63N/74 were the least stable (Table 3). Genotypes on the highest point in certain sections of the graph have the best results in environments located in the same section (Fig. 2). The hull-less line R63N/20, with average 1000-kernel weight of $44.50 \mathrm{~g}$ close to the general mean of $44.80 \mathrm{~g}$, is distinguished on the biplot. This line had the highest stability. A group of lines: R63N/61, R63N/21, R63N/1, R63N/22, R63N/18, and R63N/3, had the highest averages of 1000-kernel weight, but with different adaptations (Figs. 1 and 2): R63N/18 and R63N/1 showed specific adaptation to the conditions in 2011, and R63N/61, R63N/22, and R63N/1 showed the highest stability. These three hulled lines had the best genotype selection index 3,5, and 8 respectively (Table 3 ).

Estimates of additive gene action effects for 1000-kernel weight based on DH lines were always larger (for all DH lines, for hulled lines, and for hull-less lines) the parameter estimated on the basis of parental lines (Table 4). Additive effect estimated on the basis of observation of parental lines was significantly larger than zero in 2009, 2010, 2012, and 2013 and for average of years (Table 4). Estimates of additive gene action effects based on the all DH lines were significantly larger than zero in each year of study. Only for average of years we observed additive effect of 1000-kernel weight non-significant larger than zero (Table 4). For hulled lines, additive gene action effects were significant in 2009 and 2012; however, for hull-less lines were significant in 2009, 2011, and 2012 (Table 4). Estimates of epistasis effects for 1000-kernel weight based on all DH lines were statistically significant in 2011 and 2013; for hulled lines in 2008 and 2012; and for hull-less lines in 2009, 2010, 2011, and 2013 (Table 4). All statistically significant epistasis effects were negative (Table 4).

\section{Discussion}

The 1000-kernel weight in spring barley (Hordeum vulgare L.) is a trait determined by multiple genes that cause change in the performance of genotypes depending on the cultivation environment. In this study, the three sources of variation were highly significant. Similar results for 1000-kernel weight in barley were obtained by Swanston et al. (1997) and Boudiar et al. (2016). Kumar et al. (2017) obtained not-significant GE 
Table 4 Estimates of additive and epistasis effects for 1000-kernel weight

\begin{tabular}{|c|c|c|c|c|c|c|c|}
\hline Year & 2008 & 2009 & 2010 & 2011 & 2012 & 2013 & Mean \\
\hline \multicolumn{8}{|c|}{ Parental forms } \\
\hline$a_{\text {Parents }}{ }^{\mathrm{a}}$ & 1.36 & $2.38^{*}$ & $4.09 *$ & 1.27 & $5.26 * *$ & $7.79 * *$ & $3.69 *$ \\
\hline \multicolumn{8}{|l|}{ All lines } \\
\hline$a_{D H}^{\mathrm{b}}$ & $12.22 *$ & $15.61 *$ & $10.21 *$ & $11.50^{*}$ & $13.92 *$ & $12.73 *$ & 9.90 \\
\hline$a a_{D H}^{\mathrm{c}}$ & -0.47 & -0.05 & -0.64 & $-2.46^{* *}$ & -0.90 & $-2.05^{* * *}$ & -0.18 \\
\hline \multicolumn{8}{|c|}{ Hulled lines } \\
\hline$a_{D H}$ & 9.96 & $12.30^{*}$ & 6.05 & 6.36 & $12.17 *$ & 7.95 & 7.28 \\
\hline$a a_{D H}$ & $-1.50 * *$ & 0.38 & 0.10 & 0.93 & $-1.11 *$ & -0.02 & -0.24 \\
\hline \multicolumn{8}{|c|}{ Hull-less lines } \\
\hline$a_{D H}$ & 8.83 & $11.33^{*}$ & 6.26 & $10.56^{*}$ & $12.46^{*}$ & 8.95 & 7.15 \\
\hline$a a_{D H}$ & -0.57 & $-1.44 * *$ & $-1.17^{*}$ & $-1.65 * *$ & -0.40 & $-3.08 * * *$ & -0.25 \\
\hline
\end{tabular}

$* P<0.05 ; * * P<0.01 ; * * * P<0.001$

${ }^{a}$ The total additive effect estimated on the basis of parental observations

${ }^{\mathrm{b}}$ The total additive effect estimated on the basis of doubled haploid lines observations

${ }^{\mathrm{c}}$ The total additive-by-additive interaction effect estimated on the basis of doubled haploid lines observations

interaction for 1000-kernel weight of 25 genotypes grown in India. Apart from the GE interaction, the most important information provided by multi-location experiments, the AMMI biplot, also give a chance to visualize the main genotype effect in different environments. Studies on GE interaction are of utmost importance and can be performed using several different methods, including linear-bilinear models, which offer an improved description of the effects of interaction among factors. The additive main effects and multiplicative interaction (AMMI) model is currently one of the most popular multiplicative models. The AMMI model was originally proposed by Gollob (1968) and Mandel $(1969,1971)$ in the context of fixed effects. In this paper, we used the traditional AMMI model for fixed effects. The study of many species frequently utilized the traditional AMMI model for fixed effects (Abakemal et al. 2016; Edwards 2016; Nowosad et al. 2016; Bocianowski et al. 2019a, b). Alternative to estimation of GE interaction is the REML/BLUP method, also known as the mixed model; it has great ability to explain GE interaction, to inform about specific positive or negative interactions with environments, and to decompose the interaction in terms of "pattern" or "noise" (Piepho et al. 2008; da Silva et al. 2015). The REML/BLUP method allows the consideration of different structures of variance and covariance for the genotypes $\times$ environments effects (Ferraudo and Perecin 2014).

The AMMI model was found as a constructive tool in indicating GE interaction patterns and improving the correctness of response estimates. It enables clustering of genotypes based on similarity of response characteristics and detecting possible trends throughout environments.

Researchers gain powerful tool in identifying definite cultivars with competitive yields across different environments while applying the suggested strategy which could extract more information from the GE interaction (Nowosad et al. 2018). The 1000-kernel weight expression in South Poland is the most influenced trait by genotype and environment main effects as well as GE interaction. The significance of environment main effect resulted mainly from differences in values of precipitation between June and July in certain years. Whereas the influence of the temperature on 1000-kernel weight was low, comparing to precipitation. The observed tendencies are in accordance with physiological processes connected with grain development and formation. Water deficit could disturb grain formation and as a consequence could reduce 1000kernel weight as was observed by other authors (Kaczmarek et al. 1999; Warzecha et al. 2010, 2011).

Genotypes best matched for exact environmental conditions might be detected based on AMMI analyses which permits estimation of interaction effect of a genotype in each environment. Significant GE interaction of 1000-kernel weight was indicated with AMMI analysis application.

High genotypes stability is linked with the AMMI stability value. Determination of the main effect of the genotype, the environment, and the most meaningful GE interactions could be assessed based on the AMMI results displayed on GE biplot. The AMMI models are able to measure the weight of the environments, the genotypes, and their interactions using a value that measure genotype stability in all environments taking into account the 1000-kernel weight.

Assessment of genetic parameters has a considerable role in spring barley breeding (Pal et al. 2010; Bocianowski 2008, 2014; Bocianowski et al. 2016). The result reveals the significance of additive as well as epistasis gene effects of 1000kernel weight in 2 years (2011 and 2013) of the research. Devaux (2003) proved that more than $95 \%$ of plants are 
haploids; therefore, they possess one chromosome of each pair; this means each gene is represented by on alternative version of gene, i.e., one allele. That information is critical and crucial for our statistical model. Since after chromosome doubling each of the gene possessed identical version of alleles, there could be assumed that the plants are completely homozygous. Taking into account that information, it was possible to assess significance of additive and epistasis effect excluding dominance effect, there were no heterozygous loci in the DH line population. The existence of epistasis has significant connotation for breeders in any improving program. The epistasis effect was significant and combined with nonsignificant additive effect for 1000-kernel weight for hull-less lines in 2010 and 2013. It means that this feature was probably controlled by genes with little individual effects but tough gene-by-gene interaction effects (Bocianowski 2012a, c, 2013a, b; Bocianowski and Nowosad 2015). Epistasis effects involved in the models proved that genetic of these traits is complex and polygenic (Lander and Schork 1994; Lefebvre and Palloix 1996; Hermisson et al. 2003; Crow 2010). Epistasis has been demonstrated for numerous features in a number of cultivars of following species: barley (Kularia and Sharma 2005; Bocianowski et al. 2016), corn (Melchinger et al. 1987; Li et al. 2016), sugar beet (Abbasi et al. 2015), rice (Matsubara et al. 2015), oilseed rape (Bocianowski et al. 2017), common wheat (Bnejdi and El Gazzah 2008; Jaiswal et al. 2016), and sorghum (Finkner et al. 1981).

\section{Compliance with ethical standards}

Conflict of interest The authors declare that they have no conflict of interest.

Ethical approval This article does not contain any studies with human participants or animals performed by any of the authors.

Open Access This article is distributed under the terms of the Creative Commons Attribution 4.0 International License (http:// creativecommons.org/licenses/by/4.0/), which permits unrestricted use, distribution, and reproduction in any medium, provided you give appropriate credit to the original author(s) and the source, provide a link to the Creative Commons license, and indicate if changes were made.

\section{References}

Abakemal D, Shimelis H, Derera J (2016) Genotype-by-environment interaction and yield stability of quality protein maize hybrids developed from tropical-highland adapted inbred lines. Euphytica 209:757-769

Abbasi Z, Majidi MM, Arzani A, Rajabi A, Mashayekhi P, Bocianowski J (2015) Association of SSR markers and morpho-physiological traits associated with salinity tolerance in sugar beet (Beta vulgaris L.). Euphytica 205(3):785-797

Bnejdi F, El Gazzah M (2008) Inheritance of resistance to yellowberry in durum wheat. Euphytica 163:225-230
Bocianowski J (2008) Comparison of two methods of estimation of nonallelic interaction of QTL effects on the basis of doubled haploid lines in barley. Agric Conspec Sci 73:183-187

Bocianowski J (2012a) A comparison of two methods to estimate additive-by-additive interaction of QTL effects by a simulation study. J Theor Biol 308:20-24

Bocianowski J (2012b) Analytical and numerical comparisons of two methods of estimation of additive $\times$ additive interaction of QTL effects. Sci Agric 69(4):240-246

Bocianowski J (2012c) The use of weighted multiple linear regression to estimate QTL-by-QTL epistatic effects. Genet Mol Biol 35(4):802-809

Bocianowski J (2013a) The new method of identification of extremes groups based on epistatic interaction effect using molecular markers. Indian J Agric Sci 83(12):1372-1376

Bocianowski J (2013b) Epistasis interaction of QTL effects as a genetic parameter influencing estimation of the genetic additive effect. Genet Mol Biol 36(1):93-100

Bocianowski J (2014) Estimation of epistasis in doubled haploid barley populations considering interactions between all possible marker pairs. Euphytica 196:105-115

Bocianowski J, Krajewski P (2009) Comparison of the genetic additive effect estimators based on phenotypic observations and on molecular marker data. Euphytica 165:113-122

Bocianowski J, Nowosad K (2015) Mixed linear model approaches in mapping QTLs with epistatic effects by a simulation study. Euphytica 202:459-467

Bocianowski J, Krajewski P, Kaczmarek Z (1999) Comparison of methods of choosing extreme doubled haploid lines for genetic parameter estimation. Colloquium Biometrycze 29:193-202

Bocianowski J, Górczak K, Nowosad K, Rybiński W, Piesik D (2016) Path analysis and estimation of additive and epistatic gene effects of barley SSD lines. J Integr Agric 15(9):1983-1990

Bocianowski J, Nowosad K, Dobrzycka A, Wolko J (2017) Estimation of additive and epistatic gene effects of doubled haploid lines of winter oilseed rape (Brassica napus L.). Euphytica 213(5):122

Bocianowski J, Niemann J, Nowosad K (2019a) Genotype-byenvironment interaction for seed quality traits in interspecific cross-derived Brassica lines using additive main effects and multiplicative interaction model. Euphytica 215:7

Bocianowski J, Nowosad K, Szulc P (2019b) Soil tillage methods by years interaction for harvest index of maize (Zea mays L.) using additive main effects and multiplicative interaction model. Acta Agric Scand Sect B Soil Plant Sci 69(1):75-81

Boudiar R, Casas AM, Cantalapiedra CP, Gracia MP, Igartua E (2016) Identification of quantitative trait loci for agronomic traits contributed by a barley (Hordeum vulgare) Mediterranean landrace. Crop Pasture Sci 67(1):37-46

Buerstmayr H, Ban T, Anderson JA (2009) QTL mapping and markerassisted selection for Fusarium head blight resistance in wheat: a review. Plant Breed 129:1-26

Caliński T (1960) On a certain statistical method of investigating interaction in serial experiments with plant varieties. Pol Acad Sci Bull $(\mathrm{Cl}$ II) $1118: 565-568$

Caliński T, Czajka S, Kaczmarek Z (1987) A model for the analysis of a series of experiments repeated at several places over a period of years. I. Theory. Biuletyn Oceny Odmian 17-18:7-34

Chełkowski J, Wiśniewska H, Adamski T, Goliński P, Kaczmarek Z, Kostecki M, Perkowski J, Surma M (2000) Effects of genotypes and environmental conditions on yield reduction and mycotoxin accumulation in barley doubled haploids inoculated with Fusarium culmorum (W.G.Sm.) Sacc. J Phytopathol 148:541-545

Choo TM, Reinbergs E (1982) Estimation of the number of genes in doubled haploid populations of barley (Hordeum vulgare). Can J Genet Cytol 24:337-341

Crow JF (2010) On epistasis: why it is unimportant in polygenic directional selection. Philos Trans R Soc B 365:1241-1244 
da Silva CP, de Oliveira LA, Nuvunga JJ, Pamplona AKA, Balestre M (2015) A Bayesian shrinkage approach for AMMI models. PLoS One 10(7):e0131414. https://doi.org/10.1371/journal.pone.0131414

Desjardins AE (2006) Fusarium mycotoxins. Chemistry, genetics, and biology. The American Phytopathological Society, St. Paul, p 260

Devaux P (1986) Yield of haploid production through the bulbosum method in a winter barley breeding programme. Cereal Res Commun 14:273-279

Devaux P (2003) The Hordeum bulbosum L. method. In: Maluszynski K, Kasha K, Forster B, Szarejko I (eds) Doubled haploid production in crop plants. A manual. Kluver Academic Publishers, Dordrecht, pp 15-19

Eagles HA, Bedggood AG, Panozzo JF, Martin PJ (1995) Cultivar and environmental effects on malting quality in barley. Aust J Agric Res 46:831-844

Eberhart SA, Russell WA (1966) Stability parameters for comparing varieties. Crop Sci 6:36-40

Edwards JW (2016) Genotype×environment interaction for plant density response in maize (Zea mays L.). Crop Sci 56:1493-1505

Farshadfar E, Sutka J (2003) Locating QTLs controlling adaptation in wheat using AMMI model. Cereal Res Commun 31:249-256

Ferraudo GM, Perecin D (2014) Mixed model, AMMI and EberhartRussel comparison via simulation on genotype $\times$ environment interaction study in sugarcane. Appl Math 5:2107-2119

Finkner RE, Finker MD, Glaze RM, Maese G (1981) Genetic control for percentage grain protein and grain yield in grain sorghum. Crop Sci 21(1):139-142

Finlay KW, Wilkinson GN (1963) The analysis of adaptation in a plant breeding programme. Aust J Agric Res 14:742-754

Gauch HG, Zobel RW (1990) Imputing missing yield trial data. Theor Appl Genet 79:753-761

Gollob HF (1968) A statistical model which combines features of factor analytic and analysis of variance techniques. Psychometrika 33:73-115

Hermisson J, Hansen TF, Wagner GP (2003) Epistasis in polygenic traits and the evolution of genetic architecture under stabilizing selection. Am Nat 161(5):708-734

Jaiswal V, Gahlaut V, Meher PK, Mir RR, Jaiswal JP, Rao AR, Balyan HS, Gupta RR (2016) Genome wide single locus single trait, multilocus and multi-trait association mapping for some important agronomic traits in common wheat (T. aestivum L.). PLoS One 11(7): e0159343. https://doi.org/10.1371/journal.pone. 0159343

Kaczmarek Z (1986) The analysis of a series of experiments in incomplete block designs (in Polish). Rocz. AR Poznań 155:1-117

Kaczmarek Z, Adamski T, Surma M, Jeżowski S, Leśniewska-Frątczak M (1999) Genotype-environment interaction of barley doubled haploids with regard to malting quality. Plant Breed 118:243-247

Kasha KJ, Kao KN (1970) High frequency haploid production in barley (Hordeum vulgare L.). Nature 225:874-876

Kularia RK, Sharma AK (2005) Generation mean analysis for yield and its component traits in barley (Hordeus vulgare L.). Indian J Genet $\mathrm{Pl} \mathrm{Br}$ 65:129-130

Kumar D, Narwal S, Verma RPS, Kharub AS (2017) Genotypic and growing location effect on grain $\beta$-glucan content of barley under sub-tropical climates. Indian J Genet Pl Br 77(2):235-241

Lander ES, Schork NJ (1994) Genetic dissection of complex traits. Science 265:2037-2048

Lefebvre V, Palloix A (1996) Both epistatic and additive effects of QTLs are involved in polygenic induced resistance to disease: a case study, the interaction pepper - Phytophthora capsici Leonian. Theor Appl Genet 93:503-511

Li C, Li Y, Shi Y, Song Y, Zhang D, Buckler EB, Zhang Z, Li Y (2016) Analysis of recombination QTLs, segregation distortion, and epistasis for fitness in maize multiple populations using ultra-highdensity markers. Theor Appl Genet 129:1775-1784

Ma HX, Ge HJ, Zhang X, Lu WZ, Yu DZ, Chen H, Chen JM (2009) Resistance to Fusarium head blight and deoxynivalenol accumulation in Chinese barley. J Phytopathol 157:166-171
MacGregor AW, Bhatty RS (1993) Barley: Chemistry and Technology. American Association of Cereal Chemists, Inc, St. Paul

Mandel J (1969) The partitioning of interactions in analysis of variance. J Res Nat Bur Stand B 73:309-328

Mandel J (1971) A new analysis of variance model for non-additive data. Technometrics 13:1-18

Marin S, Ramos AJ, Cano-Sancho G, Sanchis V (2013) Mycotoxins: occurrence, toxicology, and exposure assessment. Food Chem Toxicol 60:218-237

Mather K, Jones R (1958) Interaction of genotype and environment in continuous variation. I. Description. Biometrics 14:343-359

Matsubara K, Yamamoto E, Mizobuchi R, Yonemaru J, Yamamoto T, Kato H, Yano M (2015) Hybrid breakdown caused by epistasisbased recessive incompatibility in a cross of rice (Oryza sativa L.). J Hered 106:113-122

Melchinger AE, Geiger HH, Seitz G (1987) Epistasis in maize (Zea mays L.). III. Comparison of single and three-way crosses for forage traits. Plant Breed 98:185-193

Neyman J (1932) On the methods of analysis of multiple experiments (in Polish). Rocz Nauk Rol Les 28:195-210

Nielsen LK, Cook DJ, Edwards SG, Ray RV (2014) The prevalence and impact of Fusarium head blight pathogens and mycotoxins on malting barley quality in UK. Int J Food Microbiol 179:38-49

Nowosad K, Liersch A, Popławska W, Bocianowski J (2016) Genotype by environment interaction for seed yield in rapeseed (Brassica napus L.) using additive main effects and multiplicative interaction model. Euphytica 208:187-194

Nowosad K, Tratwal A, Bocianowski J (2018) Genotype by environment interaction for grain yield in spring barley using additive main effects and multiplicative interaction model. Cereal Res Commun 46(4):729-738

Pal S, Singh T, Ramesh B (2010) Estimation of genetic parameters in barley (Hordeum vulgare L.). Crop Improv 37:52-56

Piepho HP, Möhring J, Melchinger AE, Büchse A (2008) BLUP for phenotypic selection in plant breeding and variety testing. Euphytica 161:209-228

Purchase JL, Hatting H, van Deventer CS (2000) Genotype × environment interaction of winter wheat (Triticum aestivum L.) in South Africa: II. Stability analysis of yield performance. S Afr J Plant Soil 17:101-107

Swanston JS, Ellis RP, Perez-Vendrell A, Voltas J, Molina-Cano J-L (1997) Patterns of barley grain development in Spain and Scotland and their implications for malting quality. Cereal Chem 74(4):456-461

Warzecha T, Adamski T, Kaczmarek Z, Surma M, Goliński P, Perkowski JM, Chełkowski J, Wiśniewsk H, Krystkowiak K, Kuczyńska A (2010) Susceptibility of hulled and hulless barley doubled haploids to Fusarium culmorum head blight. Cereal Res Commun 38:220 232

Warzecha T, Adamski T, Kaczmarek Z, Surma M, Chełkowski J, Wiśniewska H, Krystkowiak K, Kuczyńska A (2011) Genotype-by-environment interaction of barley DH lines infected with Fusarium culmorum (W.G.Sm.) Sacc. Field Crop Res 120:21-30

Wricke G (1962) Über eine Methode zur Erfassung der ökologischen Streubreite in Fildversuchen. Z Pflanzenzüchtg 47:92-96

Wricke G, Weber WE (1986) Quantitative genetics and selection in plant breeding. Walter de Gruyter, Berlin

Yates F, Cochran WG (1938) The analysis of groups of experiments. J Agric Sci 28:556-580

Zobel RW, Wright MJ, Gauch HG (1988) Statistical analysis of yield trial. Agron J 80:388-393

Publisher's note Springer Nature remains neutral with regard to jurisdictional claims in published maps and institutional affiliations. 